\title{
Implication of end restraint in triaxial tests on the derivation of the stress-dilatancy rule for soils having high compressibility
}

\begin{tabular}{|r|l|}
\hline Journal: & Canadian Geotechnical Journal \\
\hline Manuscript ID & cgj-2018-0343.R1 \\
\hline Manuscript Type: & Article \\
\hline Author: & 12-Aug-2018 \\
\hline Complete List of Authors: & $\begin{array}{l}\text { Muraro, Stefano; Delft university of technology, Geoscience \& } \\
\text { Engineering } \\
\text { Jommi, Cristina; Technische Universiteit Delft, Geoscience \& } \\
\text { Engineering; Politecnico di Milano, Department of Civil and } \\
\text { Environmental Engineering }\end{array}$ \\
\hline Keyword: & End restraint, triaxial tests, dilatancy, numerical analyses, peat \\
\hline $\begin{array}{r}\text { Is the invited manuscript for } \\
\text { consideration in a Special } \\
\text { Issue? : }\end{array}$ & Not applicable (regular submission) \\
\hline
\end{tabular}


Title: Implication of end restraint in triaxial tests on the derivation of the stress-dilatancy rule for soils having high compressibility

\section{Authors}

S. Muraro*

C. Jommi*,**

\section{Affiliation}

* Department of Geoscience and Engineering, Delft University of Technology, Gebouw 23, Stevinweg 1, 2628 CN, Delft, The Netherlands

**Department of Civil and Environmental Engineering, Politecnico di Milano, piazza Leonardo da Vinci 32, 20133, Milano, Italy

\section{Correspondence to}

Cristina Jommi, Department of Geoscience and Engineering

Delft University of Technology, Stevinweg 1 / PO-box 5048, 2628 CN Delft / 2600 GA Delft, The Netherlands

Tel. +31 1527 84173; e-mail: c.jommi@tudelft.nl

Date paper revised: 9 August 2018

Number of words in the main text: 5824

Number of Figures: 11

Number of Tables: 2 


\begin{abstract}
Constitutive models for soils are developed and validated against laboratory tests assuming these give representative information on the true material behaviour. However, data from standard laboratory tests reflect the sample response rather than the true material behaviour, due to non-uniformities in stresses and strains generated over the experimental test. The work examines the implications of end restraint on the definition of the stress-dilatancy rule of highly compressible soils with a finite element numerical approach. The numerical model replicates a reconstituted peat, typically characterised by a combination of high compressibility and high friction angle, which increases the severity of end restraint effects. Simulated results show that the global measurements from standard triaxial tests with rough end platens would not give the proper stress-dilatancy rule, if they were interpreted as the response of a single soil element at the constitutive level. Both overestimation and underestimation of the true dilatancy compared to the material response can be observed, depending on the deformation mode. To support the validity of the numerical results, experimental findings from drained triaxial tests on reconstituted peat are presented. Practical indications are given on how the standard interpretation of drained triaxial tests data on peats can be improved.
\end{abstract}

Keywords: End restraint, triaxial tests, dilatancy, numerical analyses, peat 


\section{INTRODUCTION}

Design and assessment procedures in many geotechnical applications require reliable constitutive models to describe the behaviour of the soil adequately. Constitutive models are usually developed and validated based on experimental laboratory tests, typically from triaxial tests. Passing from the laboratory scale to the constitutive equations, it is often assumed that the experimental test can be interpreted as a soil element test, thus representing the true material behaviour. This way of reasoning implicitly assumes that pore pressure, stresses and strains distributions are uniform within the sample. However, the boundary conditions imposed to the sample with standard laboratory devices may be far from being uniform.

Non-uniformities are introduced on the sample due to multiple factors. A first level of complexity and uncertainty comes from the assumption of uniform pore pressure both in drained and undrained tests when a finite loading rate is applied to soils with low hydraulic conductivity (Gibson and Henkel 1954; Blight 1965; Carter 1982). The result is a spurious rate effect, which is not due to time-dependent behaviour (i.e. creep), but simply comes from the coupled hydro-mechanical response (Herle and Kolymbas 2004). This problem is compounded when considering the effects of rough end platens usually employed in standard triaxial tests. Systematic attention has been given to investigate the effects of end restraint on the shear strength of both sands and clays since the 1960's, after the pioneering work of Taylor (1941). Despite the general agreement on that non-uniform conditions make the stress-strain quantities based on averaged external measurements hardly representative of the actual state of the soil in the shear zone, still some disagreement persists in quantifying their effect on the derivation of the shear strength parameters. Olson and Campbell (1964) and Bishop and Green (1965) came to the conclusion that a height to diameter ratio $H / D=2$ considerably minimises the effects of 
end restraint on the shear strength from tests on sodium-kaolinite and Ham river sand, respectively. However, the conclusion is not confirmed by the dedicated experimental work of Shockley and Ahlvin (1960) and Kirkpatrick and Belshaw (1968), who measured significant non-uniformities in the stresses and strains fields of sand samples having H/D ranging from 2 to 2.3. Significant end restraint effects leading to an overestimation of the shear strength were recently found by Kodaka et al. (2007) on normally consolidated rectangular specimens of Fukakusa clay tested in a triaxial apparatus with rough ends. More consensus is found on the influence of end platens on the volumetric behaviour upon shear. The shear stresses at the top and the bottom of the sample generated by rough end platens confine the lateral displacements to the central portion of the sample, thus preventing high degree of uniformity in stresses and strains. This typically results in higher tendency to dilate for samples tested with smooth end platens (Shockley and Ahlvin 1960; Rowe and Barden 1964; Lee and Seed 1964). However, the experimental investigation to evaluate the effects of rough end platens on the volumetric strain gradient at failure for a quartzy sand and reconstituted loess by Feda et al. (1993) concluded that no significant effects could be observed.

The predominant attention to the effects of end restraint on the shear strength of soils from the experimental viewpoint is also reflected in several numerical contributions to the problem. Nonuniformities in terms of pore pressure, stresses and strains distributions were observed from the results of FE analyses by Carter (1982), Airey (1991), Macari-Pasqualino et al. (1994), Asaoka et al. (1994) and Kodaka et al. (2007). The contributions of Schanz and Gussman (1994) and recently Jeremić et al. (2004) reported an increase in the shear strength with increasing end restraint for elastic-perfectlyplastic constitutive models. A noticeable step forward was done by Sheng et al. (1997), who discussed the implications of the end restraint on the global behaviour of soil samples. By comparing the response from global stresses-strains quantities with that at the element scale in FE analyses, Sheng et 
al. (1997) clearly showed the limitations in obtaining any information directly ascribable to the material behaviour from conventional triaxial tests. They also demonstrated that the effects of non-uniformities on the analysis of stress-strain and strength properties of the soil also depend on how the global stresses and strains are computed from triaxial tests data.

Despite the significant attention dedicated to the study of end restraint on the observed soil response and the numerical contributions which followed, the vast majority of these was devoted mainly to clarify their impact on the shear strength parameters and pore water pressure distribution. However, to the authors' knowledge, misconception introduced by disregarding the end restraint effects on the stress-dilatancy relationship of soils, hence on the description of the pre-failure behaviour, has not been tackled systematically. The importance of a correct description of the plastic deformation mechanism at failure in soils, the so called flow rule, has been shown numerically by Potts and Gens (1984), Gens and Potts (1988) and Lagioia and Panteghini (2014), among others. However, the impact of different choices for the flow rule on the performance of constitutive models for soils can be extremely important especially in reproducing the pre-failure response.

The philosophy of the work presented in this paper is to provide an insight into the implications of end restraint on the standard derivation of the stress-dilatancy relationship for soils having very high compressibility together with high friction angle, such as organic clays and peats. To this end, a series of preliminary finite element analyses has been carried out by employing the simple modified Cam clay model, MCC (Roscoe and Burland 1968). The analyses were run to support an experimental programme aimed to characterise the stress-strain behaviour of peat samples. The parameters used in the simulations are chosen to be representative of the reconstituted peat investigated by Muraro (2018). The high compressibility, combined with high friction angles, makes the geotechnical description of 
peats extremely challenging (Adams 1961; Oikawa and Miyakawa 1980; Landva and La Rochelle 1983; Yamaguchi et al. 1985b; Farrell and Hebib 1998; Kanmuri et al. 1998; Edil and Wang 2000; Cola and Cortellazzo 2005; Hendry et al. 2012). Both these aspects magnify the effects of end restraint on the failure and pre-failure responses, with peat samples experiencing volumetric and deviatoric strains not comparable with any other classical soil (Den Haan and Feddema 2013; Zhang and O'Kelly 2014).

The effects of rough end platens are quantified in terms of stress-dilatancy rule for different radial paths at constant stress ratio $\eta$, involving both lateral contraction and expansion, by elaborating the results from FE analyses replicating actual triaxial tests. The difference between the pre-failure stress-strain behaviour derived from global measurements, as conventionally done with triaxial tests data, and the "true" material response of the soil is highlighted. Results from reconstituted peat samples tested in triaxial apparatus with rough and smooth end platens are presented, to substantiate the relevance of this experimental aspect on the observed response, and to quantify the error introduced in the stressdilatancy relationship by neglecting the stress inhomogeneities due to the geometrical constraint. Eventually, a suggestion is given to start reducing the error coming from the experimental constraint.

\section{FINITE ELEMENT MODEL}

The aim of this work is to investigate the direct effect of end restraint on the drained response of soils having high compressibility. Therefore, ideally drained analyses were performed, disregarding the issues possibly raised in the interpretation of experimental data by the low hydraulic conductivity typically shown by these soils. In the practice, unless low displacement rates are adopted during the test stages, significant pore pressure gradients are generated, which cannot be disregarded in the 
interpretation of drained as well as undrained tests (Barden and McDermott 1965; Carter 1982; Sheng et al. 1997).

\section{Constitutive model of the soil}

Coupled hydro-mechanical analyses were set up with the ABAQUS standard finite-element code (Hibbitt et al. 2009). In these analyses the available Modified Cam-Clay model was adopted to preliminary analyse the response of the soil sample. The properties used to describe the material behaviour are reported in Table 1 , where $\lambda$ and $\kappa$ are the slopes of the compression and unloadingreloading lines respectively, $\mathrm{e}_{0}$ is the void ratio at a mean effective stress $\mathrm{p}_{0}^{\prime}=1 \mathrm{kPa}$, and $\mathrm{M}_{\mathrm{g}}$ is the critical stress ratio. In the first set of analyses, $M_{f}$ is set equal to $M_{g}$ under the simplifying assumption of associated flow rule. The parameters are based on the results of triaxial tests performed on reconstituted peat samples adopting smooth end platens. A hypo-elastic law with constant Poisson's ratio, v, was adopted in order to avoid the unrealistic dilatant response given at low stresses by a constant shear modulus G. The shape of the yield surface on the deviatoric $\Pi$ plane is chosen in order to properly reproduce the differences in the ultimate deviatoric stress experimentally observed along different stress paths, at the same time avoiding the tensile zones which would be encountered with a von Mises' criterion $(K=1)$ for materials having high friction angle (Hibbitt et al. 2009). The resulting shape of the yield locus on the $\Pi$ plane is sketched in Fig. 1.

\section{Insert Table 1}

\section{Insert Fig. 1}




\section{Boundary conditions and applied stress paths}

The cross-section of the sample, having a radius equal to $19 \mathrm{~mm}$ (x coordinate) and a height of $76 \mathrm{~mm}$ (y coordinate), was discretized with 1444 8-node biquadratic axis-symmetric elements with bi-linear pore pressure interpolation and reduced integration (CAX8RP) (Fig. 2a). Drainage is allowed from both the top and the bottom platens.

To simulate conventional triaxial apparatus where rough porous stones are in contact with the sample, the horizontal displacements at these two boundaries were constrained. The hypothesis of null radial displacements at the top and bottom of the sample, which seems way too conservative for classical inorganic soils, was experimentally verified by Yamaguchi (1992) for natural peat samples in standard drained triaxial compression tests. However, significant constraint to the radial displacements is offered by O-ring sealing the rubber membrane at the extremities of the sample even if lubricated end platens, which have the same diameter as the specimen, are adopted (Sheng et al. 1997).

Different radial stress paths were imposed by defining stress time histories on the top and external boundaries. Seven radial paths, at constant stress ratio $\eta=q / p^{\prime}$, where $q$ is the deviatoric stress and $p^{\prime}$ is the mean effective stress, were simulated, after isotropic compression up to $\mathrm{p}_{\mathrm{c}}{ }_{\mathrm{c}}=35 \mathrm{kPa}$ followed by isotropic unloading to $\mathrm{p}^{\prime}=15 \mathrm{kPa}$, giving an $\mathrm{OCR}=\mathrm{p}^{\prime} \mathrm{c} / \mathrm{p}^{\prime}=2.3$. The deviatoric stress was then increased at constant p' until a pre-defined stress ratio. Eventually, radial stress paths were simulated up to $\mathrm{p}^{\prime}=100 \mathrm{kPa}$ (Fig. 2b). The stress history was meant to replicate the experimental tests carried out by Muraro (2018) to characterise the stress-strain behaviour of reconstituted peat. 


\section{Insert Fig. 2}

\section{Stress and strain measures}

To provide a replica of the typical information coming from laboratory tests, global stress-strain quantities were calculated by elaborating the results of the FE analyses with the same corrections applied to the experimental data from triaxial tests. For the case of rough end platens the samples do not maintain their original aspect ratio (i.e. right cylinder), but either bulge or assume a hourglass shape depending on the imposed stress path. In both cases, in the absence of local measurements (i.e. local displacements transducers), different cross-sectional area corrections can be applied to compute the current axial stress and the representative radial strain. A detailed description of the possibilities for the area correction, depending on the available measurements, is provided by Ehrgott (1971). In this study the global radial stress is assumed to be equal to the applied cell pressure (Sheng et al. 1997; Praastrup et al. 1999), while the global axial stress has been computed by dividing the axial force measured at the top of the specimen by four different choices for the cross sectional area, namely:
a) nominal area: current contact area at the top of the specimen;
b) volumetrically equivalent right cylinder;
c) average between a) and b);
d) area at 9/10 of the height of the sample. 
The latter two choices were suggested by Sheng et al. (1997) based on a careful comparison between the global stresses and the local stresses at the element scale, from the results of FE analyses of standard drained and undrained triaxial compression tests. In practice, the most appropriate area correction should be chosen on the observed specimen geometry and measurements at the end of the test (Germaine and Ladd 1988), which reduces the degree of arbitrariness on the possible choices. However, all the four possibilities were considered in the numerical exercise.

Geometrical non-linearities were accounted for in the FE model, and natural strains were used in the material description (Ludwik 1909; Hencky 1928). The inconsistency and severe shortcomings in elaborating triaxial tests by adopting linear engineering strains have been discussed by Praastrup et al. (1999), and great care must be taken in elaborating triaxial tests on peats, especially in drained conditions, due to the large displacements experienced by peat samples (Den Haan and Feddema 2013; Zhang and O'Kelly 2014). Natural strains were chosen as they imply the validity of the additive principle in eq. (1) at large strains as well as at small strains. The global axial strain in eq. (2) has been calculated from the current height of the sample while the volumetric strain from the volume change of the sample throughout the analyses. Positive compressive stresses and strains are assumed. As done in the normal practice, in the absence of direct measurement of radial displacements the deviatoric strain has been computed from the measurement of the volume change, giving the volumetric strain $\varepsilon_{\mathrm{p}}$, and of the axial displacement, related to the axial strain $\varepsilon_{\mathrm{a}}$ :

$$
\begin{gathered}
\varepsilon_{\mathrm{p}}=\varepsilon_{\mathrm{a}}+2 \varepsilon_{\mathrm{r}}=\ln \left(\frac{\mathrm{V}_{0}}{\mathrm{~V}}\right) \\
\varepsilon_{\mathrm{q}}=\varepsilon_{\mathrm{a}}-\frac{\varepsilon_{\mathrm{p}}}{3}=\ln \left(\frac{\mathrm{H}_{0}}{\mathrm{H}}\right)-\frac{1}{3} \ln \left(\frac{\mathrm{V}_{0}}{\mathrm{~V}}\right)
\end{gathered}
$$


where $\mathrm{H}$ and $\mathrm{V}$ are the height and the volume of the sample and $\mathrm{H}_{0}, \mathrm{~V}_{0}$ the respective initial values. Dilatancy is defined as

$$
\mathrm{d}=\frac{\delta \varepsilon_{\mathrm{p}}^{\mathrm{p}}}{\delta \varepsilon_{\mathrm{q}}^{\mathrm{p}}}
$$

or equivalently (Wood 1990) by

$$
\tan \beta=\frac{\delta \varepsilon_{\mathrm{q}}^{\mathrm{p}}}{\delta \varepsilon_{\mathrm{p}}^{\mathrm{p}}}
$$

where $\delta \varepsilon_{\mathrm{p}}^{\mathrm{p}}$ and $\delta \varepsilon_{\mathrm{q}}^{\mathrm{p}}$ are the volumetric and deviatoric plastic strain increments, respectively. The plastic strains were calculated step by step as the difference between the total and the elastic strains. It is worth noting that the use of large strains introduces further non linearity in the elastic components of strains. However, the use of standard description for the elastic strain component albeit with a logarithmic measure of the strain is substantiated by literature data (e.g. Den Haan 1996; Den Haan and Feddema 2013).

\section{NUMERICAL RESULTS}

\section{Representative cross sectional area}

A possible way to discern the representativeness of the different methods for the area correction is to compare the resulting computed sample stress-strain response behaviour when rough end platens are adopted with the "true" material behaviour. Fig. 4 presents the comparison in terms of deviatoric stressaxial strain for two radial paths at $\eta=0.35$ and $\eta=1.40$, respectively below and above the $K_{0}$ line $\left(\eta_{K_{0}}\right.$ $=0.84$ for the MCC with the parameters in Table 1). It is often assumed that referring to the central 
portion of the sample, which is the farthest from the boundaries, minimises the effects of end restraint. Actually, this holds true for radial paths with $\eta<\eta_{K_{0}}$, where the lateral contraction results in a rather uniform deformation around the central portion of the sample (Fig. 3b). However, for stress paths above $\mathrm{K}_{0}$ this is not the case, due to the kinematic deformation mechanism showing significant bulging of the sample (Fig. 3c). The result is a lateral expansion of the external portion of the sample, around its mid height (Fig. 3c), which hardly participate to the axial load transfer mechanism. In the latter case, the significant stress gradient in the radial direction makes the assumption on the central portion of the sample close representing the material behaviour unrealistic.

\section{Insert Fig. 3}

\section{Insert Fig. 4}

The results in Fig. 4a show that the traditional correction with a volumetrically equivalent right cylinder tends to overestimate the stress response for a given axial strain over radial paths lying below the stress ratio corresponding to $\mathrm{K}_{0}$. Good agreement is found by using the average between the nominal area at the top of the sample and the equivalent cylinder. However, for radial paths above the $\mathrm{K}_{0}$ condition, the same correction suffers similar problems as the equivalent right cylinder correction, due to an overestimation of the effective cross section area. This drawback was pointed out already by Sheng et al. (1997) from the simulation of the shearing stage of standard undrained triaxial tests. For the radial path at $\eta=1.40$, above the stress ratio corresponding to the $K_{0}$ condition, choosing the cross sectional area at $9 / 10$ of the height of the sample from the FE analyses results in the closest 
representation of the material behaviour (Fig. 4b). Based on these observations, in the following discussion the results will be presented by correcting the area in two different ways, depending on the stress ratio, $\eta$ :

a) average between the nominal area and the volumetrically equivalent right cylinder for radial paths with $\eta<\eta_{\mathrm{K}_{0}}$

b) area at 9/10 the height of the sample for radial paths with $\eta>\eta_{K_{0}}$.

\section{Stress-dilatancy relationship}

The stress-dilatancy relationship (eq. (3)) obtained by elaborating the FE analyses results at the sample level (global quantities) is reported in Fig. 5. The "true" material behaviour, as modelled by the MCC, is displayed for the sake of comparison, together with numerical results of tests replicating the response of samples ideally tested with perfectly smooth bases. These allow validating the numerical model before analysing the effect of end restraint.

The shear stresses generated at the top and the bottom of the sample tend to reduce the lateral contraction and expansion compared to smooth conditions. For radial paths below $\mathrm{K}_{0}$, higher deviatoric strains are expected at a given axial stress, while the opposite occurs for radial paths above $\mathrm{K}_{0}$. Consistently, the numerical results in Fig. 5 underestimate the dilatancy for the stress paths below $\eta_{\mathrm{K}_{0}}$ and overestimate it for radial paths which imply lateral expansion. It is worth observing that the lowest discrepancy between the dilatancy derived at the sample scale and the material dilatancy occurs for a stress path corresponding to $\mathrm{K}_{0}\left(\eta_{\mathrm{K}_{0}}=0.84\right)$. Strictly speaking, it is only along a stress path implying 
zero lateral displacement that the end restraint effect is minimised and the true material behaviour is theoretically recovered. In Fig. 5 the result for $\eta=0.84$ slightly differs from the expected one, due to the previous loading history simulated in the analyses (isotropic loading and unloading) which is responsible for the deviation due to a small irreversible end restraint effect.

\section{Insert Fig. 5}

\section{A MODELLING EXERCISE}

If the FE results in Fig. 5 were processed as if they were representing the material behaviour, as typically done in processing experimental triaxial test data, the stress-dilatancy relationship would be obtained by interpolating the points displayed in Fig. 6 referred to as sample behaviour. Fig. 6a shows that by doing so, the derived stress-dilatancy relationship has a different shape compared to the true one (indicated in the figure as material behaviour), and also that it tends to overestimate the critical stress ratio $M_{g}$ for which $d=0$. In Fig. 6a the material behaviour obeys to the $\mathrm{MCC}$ with $\mathrm{M}_{\mathrm{g}}=1.75$ while the sample behaviour approaches null dilatancy for $\mathrm{M}_{\mathrm{g}}=2$. The difference between the inclination of the plastic strain increment vectors, $\Delta \beta$, predicted by the sample behaviour compared to the material behaviour is displayed in Fig. $6 \mathrm{~b}$ as a function of the stress ratio. Both overestimation and underestimation of the inclination were found for low and high stress ratios respectively, in the order of $2^{\circ}$ and $-8^{\circ}$. 


\section{Insert Fig. 6}

Fig. 7 reports the deviatoric stress-strain response along two radial paths at $\eta=0.35$ and $\eta=1.40$ predicted by using the stress-dilatancy relationship from the sample behaviour and material behaviour in Fig. 6a on a soil element. For radial paths below $\mathrm{K}_{0}$ (Fig. 7a), far from failure conditions, misinterpreting the material flow rule results in overestimating the strains for a given stress level. On the contrary, for radial paths close to the failure state, and in general above $\mathrm{K}_{0}$, (Fig. $7 \mathrm{~b}$ ) the sample behaviour overestimates the deviatoric stress for a given strain level compared to the material behaviour. The difference may reach non-negligible values, with remarkable implications on the assessment of ultimate limit states. However, also a bias in the deformational pre-failure response below the $\mathrm{K}_{0}$ line would be introduced by misinterpreting the stress-dilatancy relationship, which might influence serviceability limit states assessment.

\section{Insert Fig. 7}

\section{EXPERIMENTAL EVIDENCE}


The numerical results offer the possibility for a critical evaluation of experimental tests aimed to describe the failure and pre-failure response of peats. Dedicated experimental tests were performed to effectively quantify the influence of end restraint on the observed response of peat samples.

Reconstituted samples were chosen to minimise the heterogeneity of natural peats. The reconstituted samples were prepared by mixing the natural material with demineralised water to a slurry with water content of $855 \%$, corresponding to 1.4 times the liquid limit. The material was then consolidated in a floating consolidometer under a total vertical stress of $10 \mathrm{kPa}$ for 48 hours and eventually mounted in a GDS triaxial apparatus. A suction cap was used to assure perfect contact between the load cell and the top cap. The volume change and the axial displacement were recorded with a digital pressure/volume controller and an external linear transducer (the calibration of the equipment is reported in Muraro (2018))

Relevant index properties of the samples are reported in Table 2, together with the isotropic preconsolidation stress at the start of the test, $\mathrm{p}_{0}^{\prime}$, the isotropic stress at the end of the test, $\mathrm{p}_{\mathrm{t}}$, and an indication of the stress path followed during each test. The specific gravity, Gs, and the organic content, OC, were determined in accordance with the D5550-14 (2014) and the D2974-14 (2014).

\section{Insert Table 2}

The testing programme consisted of a series of drained triaxial tests, including multiple stress paths which allowed to explore different loading conditions. The nominal dimensions of the specimens were 
$50 \mathrm{~mm}$ in diameter and $100 \mathrm{~mm}$ in height. All the tested were performed under stress control assuring limited excess pore pressure generation due to the loading rate. To accelerate the consolidation process, lateral filter paper strips were used, with free lower ends to avoid introducing lateral constraint. The resulting average axial displacement rate, $\dot{\mathrm{u}}_{\mathrm{a}}$, reported in Table 2, is approximately ten time lower than that required to guarantee a degree of dissipation of pore pressure of 95\% (Blight 1963).

Sample 1 and sample 2 were isotropically compressed up to $\mathrm{p}_{\mathrm{t}}^{\prime}=74 \mathrm{kPa}$ and $\mathrm{p}_{\mathrm{t}}=100 \mathrm{kPa}$, while a $\mathrm{K}_{0}$ compression test was performed on sample 3 up to $\mathrm{p}_{\mathrm{t}}^{\prime}=70 \mathrm{kPa}$ (Fig. 8a). The $\mathrm{K}_{0}$ compression test was performed with a radial stress ramp with volume change and axial displacement back measurement allowing for automatic adjustment to guarantee negligible radial strains. Sample 4 was firstly isotropically consolidated up to a mean effective stress $\mathrm{p}_{0}^{\prime}=32 \mathrm{kPa}$ and subsequently isotropically unloaded to give an initial overconsolidation ratio $\mathrm{OCR}=\mathrm{p}^{\prime}{ }^{\prime} / \mathrm{p}^{\prime}$ of about 2 . The final shearing stage consisted in a series of mixed isotropic and deviatoric loading steps as summarised in Fig. 8b. On sample 2 the end restraint effects were limited by interposing a perforated plastic disk and a perforated nitrile membrane, $0.1 \mathrm{~mm}$ thick, between the filter paper and the sample.

\section{Insert Fig. 8}

\section{Isotropic response}

The results obtained from isotropic compression on sample 1 and sample 2 are displayed in Figs. 9a and $9 \mathrm{~b}$. To evaluate the deformation response of the samples, the isotropic compression was performed by controlling separately the axial and the radial stresses, and measuring the axial displacement and the 
volume change separately. In Fig. 9a the incremental volumetric over axial strain ratio $\delta \varepsilon_{\mathrm{p}} / \delta \varepsilon_{\mathrm{a}}$, is given as a function of the mean effective stress.

Insert Fig. 9

If the sample response were perfectly isotropic, the incremental strain ratio would be equal to $\delta \varepsilon_{\mathrm{p}} / \delta \varepsilon_{\mathrm{a}}$ $=3$. At the beginning of the compression stage the experimental ratio is higher due to the reorientation of the initial fabric, created during the 1-D preparation in the consolidometer tube under a small vertical stress and no lateral strain. However, the asymptotic ratio is of relevance to quantify the effect of the kinematic constraint imposed by the end restraint.

For sample 1, tested with rough end platens the incremental ratio between the volumetric and axial strain attains a value lower than that corresponding to the isotropic response. The result is due to the shear stresses between the soil sample and the porous stones, which constrained the lateral contraction during isotropic compression, hence inducing non-null deviatoric strain. The corresponding impact on the stress-dilatancy rule is reported in Fig. 9b, which shows that the inclination of the plastic strain increment vectors is about $6^{\circ}$ to the horizontal. However, the observed inclination of the plastic strain increment vectors cannot be ascribed to an asymptotic anisotropic response, as the data on sample 2 , tested with smooth end platens, demonstrate. At increasing stress, the incremental strain ratio tends to the expected value of 3 for the isotropic material response. 
Previous tests in the literature indicate that natural fibrous peats may exhibit inherent anisotropy due to the orientation of the big fibres within the peat fabric (Landva and La Rochelle 1983; Yamaguchi et al. 1985a,b). However, the maximum length of the fibres in the tested peat was $3 \mathrm{~mm}$, and they were randomly distributed during the 1-D preparation procedure. After re-orientation of the fabric from 1-D to isotropic, the true material response appears to be isotropic as well (sample 2 Fig. 9a). However, the sample response is affected by the kinematic constraint at the top and the bottom, and eventually appears anisotropic. It is worthwhile remarking that the FE simulation of the isotropic compression test on a constrained sample of a material obeying the MCC model with the parameters reported in Table 1, gives a prediction of the incremental strain ratio which qualitatively reproduces the observed experimental response. The quantitative difference between the inclination of the calculated and observed vectors is mostly due to the choice for a basic MCC model to simulate the more complicated material behaviour of peat. Possible concomitant constraint provided by the connection of the external membrane with the top cap may play a small role too, which was not accounted for in the numerical analyses.

\section{Deviatoric response}

The deviatoric response was investigated by means of the $\mathrm{K}_{0}$ radial path (Fig. 8a) and the mixed incrementally isotropic and deviatoric path on sample 4 (Fig. 8b) where rough end platens were used. The experimental data from the different test stages were elaborated to give a comprehensive picture of the stress-dilatancy rule, as it appears from the sample behaviour (Fig. 10).

\section{Insert Fig. 10}


Following the same approach described for the elaboration of the data in Fig. 6a, the experimental data from sample 4 are interpolated to give the sample $\mathrm{d}-\eta$ sample behaviour. To fit the experimental results in Fig. 10, the generalised flow rule proposed by McDowell and Hau (2003) is used. The adopted equation allows high flexibility in the shape of the stress-dilatancy rule through the coefficient $\chi$, though keeping the formulation extremely simple. It is worth remarking that the same formulation has been used by Ohmaki (1982), Alonso et al. (1990) and Yu (2007), among others. The stress dilatancy rule reads:

$$
\mathrm{d}=\frac{\mathrm{M}_{\mathrm{g}}^{2}-\eta^{2}}{\chi \eta}
$$

To interpolate the experimental data, the apparent critical stress ratio was set equal to the asymptotic stress ratio reached by sample $4, \mathrm{M}_{\mathrm{g}}=\eta_{\mathrm{u}}=2.57$ (Fig. $8 \mathrm{~b}$ ) and the shape factor to a value $\chi=3.5$.

\section{DISCUSSION}

Based on the numerical results reported before, it is expected that the $d-\eta$ values in Fig. 10 lay below the true material response for $\eta<\eta_{K_{0}}$ and above it for $\eta>\eta_{K_{0}}$. Also, the critical stress ratio of the material should be lower than the one elaborated from the triaxial tests with rough end platens. Despite the true $d-\eta$ rule for the tested peat is not known, in principle it should satisfy three conditions:

(i) $d \rightarrow \infty$ for $\eta=0$, due to the observed isotropic response in isotropic compression (Fig. 9a);

(ii) $d=$ observed $d$, for $\eta=\eta_{K_{0}}$, as a $K_{0}$ path rules out the end restraint effect;

(iii) $d=0$ for $\eta=M_{g}$, where $M_{g}$ gives the critical stress ratio.

Based on these constraints and exploiting the fundamental information on $\mathrm{K}_{0}$ coming from the experimental tests, the modelling exercise presented in the previous section is further exploited in an 
attempt to clean the experimental data from the effect of the end restraint. The calculated lateral pressure ratio derived from the experimental data along the radial path on sample 3 allows to define a value of $\mathrm{K}_{0}=0.33$ for the tested peat, in the range indicated by previous findings (Den Haan and Kruse 2007; Edil and Wang 2000; Hayashi et al. 2012). The critical stress ratio determined from the undrained triaxial test with smooth end platens (TxCU) for this peat, $\mathrm{M}_{\mathrm{g}}=1.75$ (see Table 1), gives a friction angle $\varphi^{\prime}=42.6^{\circ}$. According to the simplified Jaky's formula (Jaky 1948), $\mathrm{K}_{0} \cong 1-\sin \varphi^{\prime}$, the corresponding $\mathrm{K}_{0}$ value would be $\mathrm{K}_{0}=0.32$, which well matches the value determined from the $\mathrm{K}_{0}$ triaxial test. If the ultimate stress ratio $\eta_{\mathrm{u}}=2.57$ derived from sample 4 (Fig. $8 \mathrm{~b}$ ) was used as critical stress ratio, a much lower value $\mathrm{K}_{0}=0.1$ would be obtained, in contrast to the experimental result on sample 3.

Eq. (5) is now used to propose a stress-dilatancy relationship which satisfies the three conditions above. The value of $\chi$ is chosen in such a way that the flow rule predicts zero lateral strain for a stress path corresponding to the $\mathrm{K}_{0}$ condition expressed through the Jaky's simplified equation as

$$
\eta_{\mathrm{K}_{0}}=\frac{3 \mathrm{M}_{\mathrm{g}}}{6-\mathrm{M}_{\mathrm{g}}}
$$

Along a $\eta_{\mathrm{K}_{0}}$ radial path, the constraint of null radial strain implies

$$
\mathrm{d}=\frac{3 \lambda-\kappa}{2 \lambda}
$$


if the elastic component of the deviatoric strain is neglected for the sake of simplicity (Alonso et al. 1990). Combining eqs. (5) to (7),

$$
\chi=\frac{2 \lambda M_{g}\left[\left(6-M_{g}\right)^{2}-9\right]}{9 \lambda-\kappa \frac{M_{g}}{6-M}}
$$

with the compression indexes $(\lambda=2.0, \kappa=0.3)$ in Table 1 and the critical stress ratio $\mathrm{M}_{\mathrm{g}}=1.75$, a value of $\chi=0.98$ is found. The resulting stress-dilatancy relationship is plotted in Fig. 11a, together with the experimental data from sample 3, sample 4 and the TxCU test with smooth end platens. The data from the constant deviatoric stress path "BC" and the portion of the path "CD" below the $\mathrm{K}_{0}$ line (Fig. 8b) lie below the model stress-dilatancy relationship. At increasing stress ratio along the path "CD" the experimental results move to the right hand side of the theoretical response, consistently with the previous numerical findings.

\section{Insert Fig. 11}

The experimental data on sample 4 intersect the proposed stress-dilatancy rule for a stress ratio of $\eta_{K_{0}}$ $=1.2$, as expected. If the proposed stress-dilatancy law in Fig. 11a were assumed to represent the "true" material behaviour and the experimental results were not corrected, an error on the inclination of the plastic strain increment vectors would occur. The difference in inclination between the "true" values and the values derived without correcting for the end restraint, $\Delta \beta$, is in the range of $7^{\circ}$ to $-15^{\circ}$ for low and high stress ratios respectively. This is reflected in an appreciable change of the shape of the plastic potential, as shown in Fig. $11 \mathrm{~b}$. 
In the attempt to verify the validity of the proposed "true" material stress-dilatancy function for the tested peat, the radial paths in Fig. $2 \mathrm{~b}$ have been reproduced numerically, by simulating the triaxial test and including end restraint. Compared to the previous numerical results, only the $d-\eta$ relationship was changed, by using eq. (5) with $\mathrm{M}_{\mathrm{g}}=1.75$ and $\chi=0.98$. All the other parameters were kept as in Table 1. As displayed in Fig. 11a, by using the proposed $d-\eta$ relationship, the sample behaviour observed from the experimental triaxial tests with rough end platens was recovered. The agreement between the numerical results and the experimental data is more than satisfactory for $\eta<\eta_{\mathrm{K}_{0}}$. For radial paths above the $\mathrm{K}_{0}$ line, the numerical results predict a higher dilatancy than expected based on the material behaviour. However, the numerical results lie below the experimental ones, due to the latter tending to a higher value of ultimate stress ratio, which can be ascribed to deviatoric hardening (e.g. Nova 1977). By introducing the latter ingredient in a constitutive model higher ultimate stress ratio could be reproduced (Muraro 2018).

\section{CONCLUSIONS}

An experimental and modelling exercise was proposed to evaluate the effect of triaxial tests issues in the derivation of the stress-dilatancy law. The effects of the end restraint on the shear strength at failure obtained from triaxial compression tests have been intensively investigated in the past, both experimentally and numerically. However, inferring the correct stress-dilatancy relationship for the entire pre-failure range is essential in view of deformation analyses and of serviceability limit states assessment. So far, scarce attention has been given to the end restraint effects on this fundamental ingredient of any constitutive model. The consequences of end restraint on the derivation of the stressdilatancy relationship are particularly relevant for soft organic soils such as peats, where the high 
compressibility combined with the high friction angle increases the non-uniformities in stresses and strains within the sample during a standard laboratory test.

Experimental results from triaxial compression tests with rough and smooth end platens showed the influence of the kinematic constraint on the deformation mode of peat samples. End restraint plays a role at any stage of the test, which clearly emerges from isotropic compression paths on isotropic samples. When rough end platens were used in the experimental test, the strain response appeared as if were anisotropic, with plastic strain increment vectors inclined of about $6^{\circ}$ with respect to the horizontal.

A series of finite element analyses of triaxial tests were run to highlight the difference between the material behaviour at the constitutive level and the sample behaviour. The stress-dilatancy relationship reconstructed from global stress-strain variables in the numerical analyses differs substantially from the material flow rule, if rough end platens are introduced. In particular, the numerical results showed that for radial stress paths below the stress ratio which corresponds to the $\mathrm{K}_{0}$ condition the dilatancy is underestimated, while for radial path above $\mathrm{K}_{0}$ it is overestimated. Moreover, when the stress-dilatancy relationship is derived from global stress-strain variables overestimation occurs of the critical stress ratio corresponding to null dilatancy. As a whole, the incorrect interpretation of the flow rule due to end restraint effects may have relevant engineering implications on both serviceability and ultimate limit states, by overestimating the displacements or the shear strength for loading paths below and above the $\mathrm{K}_{0}$ condition, respectively.

The analysis of the experimental and numerical data including rough end platens allowed providing a practical approach to correct the interpretation of drained triaxial tests on peat, in an attempt to clean the observed data from end restraint effects. Based on simple observations coming from a $\mathrm{K}_{0}$ test in the 
triaxial apparatus and undrained compression tests with smooth end platens, a corrected stressdilatancy relationship for the reconstituted peat could be proposed and numerically validated.

\section{ACKNOWLEDGEMENT}

The financial support of the Dutch Organisation for Scientific Research (NWO), under the project "Reliability-Based Geomechanical Assessment Tools for Dykes and Embankments in Delta Areas13864 (Reliable Dykes)" is gratefully acknowledged. The authors wish to thank Dr. Hongfen Zhao for her invaluable help with the experimental tests and fruitful discussions.

\section{REFERENCES}

Adams, J.I. 1961. Laboratory compression tests on peat. In 7th Muskeg Research Conference. NCR, Ottawa. pp. 36-54.

Airey, D.W. 1991. Finite element analyses of triaxial tests with different end and drainage conditions. In Proceedings of the 7th International Conference on Computer Methods and Advances in Geomechanics. Edited by Beer and Booker and Carter. Balkema. pp. 225-230.

Alonso, E.E., Gens, A., and Josa, A. 1990. A constitutive model for partially saturated soils. Géotechnique 40(3): 405-430.

Asaoka, A., Nakano, M., and Noda, T. 1994. Soil-water coupled behaviour of saturated clay near/at critical state. Soils and foundations 34(1): 91-105. 
Barden, L., and McDermott, J.W. 1965. Use of free ends in triaxial testing of clays. Journal of the Soil Mechanics and Foundations Division 91(6): 1-23.

Bishop, A.W., and Green, G.E. 1965. The influence of end restraint on the compression strength of a cohesionless soil. Géotechnique 15(3): 243-266.

Blight, G.E. 1963. The effect of nonuniform pore pressures on laboratory measurements of the shear strength of soils. In Laboratory shear testing of soils. ASTM International. pp. 173-184.

Blight, G.E. 1965. Shear stress and pore pressure in triaxial testing. Journal of the Soil Mechanics and Foundations Division 91(6): 25-40.

Carter, J.P. 1982. Predictions of the non-homogeneous behaviour of clay in the triaxial test. Géotechnique 32(1): 55-58.

Cola, S., and Cortellazzo, G. 2005. The shear strength behavior of two peaty soils. Geotechnical and Geological Engineering 23(6): 679-695.

D2974-14, 2014. Standard test methods for moisture, ash, and organic matter of peat and other organic soils. American Society of Testing and Materials.

D5550-14, 2014. Standard test method for specific gravity of soil solids by gas pycnometer. American Society of Testing and Materials.

Den Haan, E.J. 1996. A compression model for non-brittle soft clays and peat. Géotechnique 46(1): 116.

Den Haan, E.J., and Feddema, A. 2013. Deformation and strength of embankments on soft Dutch soil. Proceedings of the Institution of Civil Engineers-Geotechnical engineering 166(3): 239-252. 
Den Haan, E.J., and Kruse, G.A.M. 2007. Characterisation and engineering properties of Dutch peats. In Proceedings of the Second International Workshop of Characterisation and Engineering Properties of Natural Soils Singapore. pp. 2101-2133.

Edil, T.B., and Wang, X. 2000. Shear strength and K0 of peats and organic soils. In Geotechnics of high water content materials. ASTM International. pp. 209-225.

Ehrgott, J.Q. 1971. Calculation of stress and strain from triaxial test data on undrained soil specimens. Army engineer waterways experiment station.

Farrell, E.R., and Hebib, S. 1998. The determination of the geotechnical parameters of organic soils. In Proceedings of International Symposium on problematic soils. Edited by Yanagisawa and Moroto and Mitachi. Balkema, Rotterdam, The Netherlands. pp. 33-36.

Feda, J., Boháč, J., and Herle, I. 1993. End restraint in triaxial testing of soils. Acta Technica CSAV 38: $197-220$.

Gens, A., and Potts, D.M. 1988. Critical state models in computational geomechanics. Engineering Computations 5(3): 178-197.

Germaine, J.T., and Ladd, C.C. 1988. Triaxial Testing of Saturated Cohesive Soils. In Advanced Triaxial Testing of Soil and Rock. Edited by Donaghe and Chaney and Silver. ASTM. pp. 421-459.

Gibson, R.E., and Henkel, D.J. 1954. Influence of duration of tests at constant rate of strain on measured "drained" strength. Géotechnique 4(1): 6-15. 
Hayashi, H., Yamazoe, N., Mitachi, T., Tanaka, H., and Nishimoto, S. 2012. Coefficient of earth pressure at rest for normally and overconsolidated peat ground in Hokkaido area. Soils and Foundations 52(2): 299-311.

Hencky, H. 1928. Über die Form des Elastizitätsgesetzes bei ideal elastischen Stoffen. Zeitschrift für technische Physik 6: 215-220.

Hendry, M.T., Sharma, J.S., Martin, C.D., and Barbour, S.L. 2012. Effect of fibre content and structure on anisotropic elastic stiffness and shear strength of peat. Canadian Geotechnical Journal 49(4): 403415.

Herle, I., and Kolymbas, D. 2004. Hypoplasticity for soils with low friction angles. Computers and Geotechnics 31(5): 365-373.

Hibbitt, D., Karlsson, B., and Sorensen, P. 2009. ABAQUS standard user's manual, version 6.9-EF, Pawtucket, RI, USA.

Jaky, J. 1948. State of stress at great depth. In Proceedings of the Second International Conference of Soil Mechanics and Foundation Engineering pp. 103-107.

Jeremić, B., Yang, Z.X., and Sture, S. 2004. Numerical assessment of the influence of end conditions on constitutive behavior of geomaterials. Journal of engineering mechanics 130(6): 741-745.

Kanmuri, H., Kato, M., Suzuki, O., and Hirose, E. 1998. Shear strength of K0 consolidated undisturbed peat. In Proc. of the Int. Symposium on Problematic Soils. Edited by Yanagisawa and Moroto and Mitachi. Balkema, Sendai, Japan. pp. 25-28. 
Kirkpatrick, W.M., and Belshaw, D.J. 1968. On the interpretation of the triaxial test. Géotechnique 18(3): 336-350.

Kodaka, T., Higo, Y., Kimoto, S., and Oka, F. 2007. Effects of sample shape on the strain localization of water-saturated clay. International journal for numerical and analytical methods in geomechanics 31(3): 483-521.

Lagioia, R., and Panteghini, A. 2014. The influence of the plastic potential on plane strain failure. International Journal for Numerical and Analytical Methods in Geomechanics 38(8): 844-862.

Landva, A.O., and La Rochelle, P. 1983. Compressibility and shear characteristics of Radforth peats. In Testing of peats and organic soils. ASTM International. pp. 157-191.

Lee, K.L., and Seed, H.B. 1964. Discussion of "Importance of free ends in triaxial testing". Journal of Soil Mechanics \& Foundations Division 90(6): 167-179.

Ludwik, P. 1909. Elemente der technologischen Mechanik. Springer-Verlag.

Macari-Pasqualino, E.J., Runesson, K., and Sture, S. 1994. Response prediction of granular materials at low effective stresses. Journal of geotechnical engineering 120(7): 1252-1268.

McDowell, G.R., and Hau, K.W. 2003. A simple non-associated three surface kinematic hardening model. Géotechnique 53(4): 433-437.

Muraro, S. 2018. PhD dissertation. Delft University of Technology, in preparation.

Nova, R. 1977. On the hardening of soils. Archiwum Mechaniki Stosowanej 29(3): 445-458. 
Ohmaki, S. 1982. Stress-strain behaviour of anisotropically, normally consolidated cohesive soil. In Proc. 1st Int. Symp. Num. Mod. Geomech., Zurich, Switzerland. pp. 250-269.

Oikawa, H., and Miyakawa, I. 1980. Undrained shear characteristics of peat. Soils and foundations 20(3): 91-100.

Olson, R.E., and Campbell, L.M. 1964. Discussion on importance of free ends in triaxial testing. Journal of the Soil Mechanics and Foundations Division 90(6): 167-173.

Potts, D.M., and Gens, A. 1984. The effect of the plastic potential in boundary value problems involving plane strain deformation. International Journal for Numerical and Analytical Methods in Geomechanics 8(3): 259-286.

Praastrup, U., Jakobsen, K.P., and Ibsen, L.B. 1999. Two theoretically consistent methods for analysing triaxial tests. Computers and Geotechnics 25(3): 157-170.

Roscoe, K.H., and Burland, J.B. 1968. On the generalized stress-strain behaviour of wet clay. In Engineering plasticity. Edited by Heyman and Leckie. Cambridge University Press, Cambridge. pp. $535-609$.

Rowe, P.W., and Barden, L. 1964. Importance of free ends in triaxial testing. Journal of Soil Mechanics \& Foundations Division 90(1): 1-27.

Schanz, T., and Gussman, P. 1994. The influence of geometry and end restraint on the strength in triaxial compression in numerical simulation. In Numerical Methods in Geotechnical Engineering. Edited by Smith. Balkema, Rotterdam. pp. 129-133. 
Sheng, D., Westerberg, B., Mattsson, H., and Axelsson, K. 1997. Effects of end restraint and strain rate in triaxial tests. Computers and Geotechnics 21(3): 163-182.

Shockley, W.G., and Ahlvin, R.G. 1960. Nonuniform conditions in triaxial test specimens. In Research Conference on Shear Strength of Cohesive Soils. ASCE, University of Colorado, Boulder, Colorado. pp. 341-357.

Taylor, D.W. 1941. Cylindrical compression research program on stress-deformation and strength characteristics of soils. Massachusetts Institute of Technology.

Wood, D.M. 1990. Soil behaviour and critical state soil mechanics. Cambridge university press.

Yamaguchi, H. 1992. Consideration on method of triaxial test on highly organic soil. Doboku Gakkai Ronbunshu 1992(457): 13-22.

Yamaguchi, H., Ohira, Y., and Kogure, K. 1985a. Volume change characteristics of undisturbed fibrous peat. Soils and foundations 25(2): 119-134.

Yamaguchi, H., Ohira, Y., Kogure, K., and Mori, S. 1985b. Undrained shear characteristics of normally consolidated peat under triaxial compression and extension conditions. Soils and Foundations 25(3): 118.

Yu, H.S. 2007. Plasticity and geotechnics. Springer Science \& Business Media.

Zhang, L., and O'Kelly, B.C. 2014. The principle of effective stress and triaxial compression testing of peat. Proceedings of the Institution of Civil Engineers-Geotechnical Engineering 167(1): 40-50. 


\section{LIST OF FIGURES}

Fig. 1. Shape of the yield locus on the deviatoric $\Pi$ plane for $K=0.778$ (chosen value) and $K=1$ (von Mises)

Fig. 2. Sketch of the triaxial specimen with the boundary conditions used in the finite element model (a); (b) stress histories imposed to the specimen in the numerical analyses.

Fig. 3. Contour plots of the axial strain from the numerical analyses: (a) undeformed configuration; deformed configuration for (b) stress ratio $\eta=0.35$ and (c) $\eta=1.40$.

Fig. 4. Comparison between the deviatoric stress-axial strain response after the four different cross sectional area corrections considered and the material response from smooth FE simulations for radial paths with (a) $\eta=0.35$ and (b) $\eta=1.40$.

Fig. 5. Stress-dilatancy relationship $d-\eta$ from the FE results at the sample level (global quantities) for both smooth and rough end platens compared to the input MCC law.

Fig 6. Stress-dilatancy relationship (a) and (b) inclination of the plastic strain increment vectors obtained by fitting the results of radial paths from conventional triaxial tests with rough end platens.

Fig. 7. Comparison between material and sample behaviour as predicted from a single element test based on the results from triaxial tests with rough end platens for two radial path: (a) $\eta=0.35$ and (b) $\eta$ $=1.40$. 
Fig. 8. Experimental isotropic stress paths and $\mathrm{K}_{0}$-consolidation (a); (b) mixed isotropic-deviatoric path.

Fig. 9. Incremental volumetric over axial strain ratio (a); inclination with respect to the horizontal of the plastic strain increment vectors during isotropic compression of reconstituted peat samples with rough and smooth end platens (b).

Fig. 10. Stress-dilatancy relationship derived from the experimental results on sample 4 with rough end platens.

Fig. 11. Proposed stress-dilatancy relationship for the tested reconstituted peat ruled out by the end restraint effect (a); plastic potential derived from for the sample behaviour and proposed plastic potential (b). 


\section{LIST OF SYMBOLS}

H sample height

D sample diameter

V sample volume

$\mathrm{H}_{0} \quad$ initial sample height

$\mathrm{D}_{0} \quad$ initial sample diameter

$\mathrm{V}_{0} \quad$ initial sample volume

$\lambda$ slope of the isotropic normal compression line

$\kappa \quad$ slope of the isotropic unloading-reloading line

$v \quad$ Poisson's ratio

G shear modulus

$\mathrm{k}_{\mathrm{s}} \quad$ saturated hydraulic conductivity

$\mathrm{e}_{0} \quad$ initial void ratio

Gs specific gravity

OC organic content

$\mathrm{p}^{\prime} \quad$ mean effective stress

$\mathrm{p}_{\mathrm{c}}^{\prime} \quad$ preconsolidation mean effective stress

$\mathrm{p}_{\mathrm{t}}^{\prime} \quad$ maximum mean effective stress applied in the triaxial apparatus

q deviatoric stress

OCR overconsolidation ratio

$\mathrm{K}_{0} \quad$ coefficient of earth pressure at rest

$\eta \quad$ stress ratio

$\eta_{K_{0}} \quad$ stress ratio along $K_{0}$ path 
$\eta_{\mathrm{u}} \quad$ asymptotic stress ratio

$\mathrm{M}_{\mathrm{f}} \quad$ stress ratio associated to the horizontal tangent of the yield locus

$\mathrm{M}_{\mathrm{g}} \quad$ stress ratio at critical state

$\mathrm{K} \quad$ shape factor of the yield locus on the deviatoric $\Pi$ plane

$\dot{\mathrm{u}}_{\mathrm{a}} \quad$ axial displacement rate

$\varepsilon_{\mathrm{a}} \quad$ axial strain

$\varepsilon_{\mathrm{r}} \quad$ radial strain

$\varepsilon_{\mathrm{p}} \quad$ volumetric strain

$\varepsilon_{\mathrm{q}} \quad$ deviatoric strain

$\delta \varepsilon_{\mathrm{a}} \quad$ axial strain increment

$\delta \varepsilon_{\mathrm{p}} \quad$ volumetric strain increment

$\delta \varepsilon_{\mathrm{p}}^{\mathrm{p}} \quad$ volumetric plastic strain increment

$\delta \varepsilon_{\mathrm{q}}^{\mathrm{p}} \quad$ deviatoric plastic strain increment

d dilatancy

$\beta \quad$ inclination to the horizontal of the plastic strain vectors

$\chi \quad$ coefficient for the stress-dilatancy relationship

$\varphi^{\prime} \quad$ friction angle 
Table 1. Material parameters used in the numerical simulations.

\begin{tabular}{lll}
\hline Parameter & Units & Numerical value \\
\hline$\kappa$ & {$[-]$} & 0.3 \\
$\lambda$ & {$[-]$} & 2.0 \\
$v$ & {$[-]$} & 0.2 \\
$\mathrm{p}_{0}^{\prime}$ & {$[\mathrm{kPa}]$} & 1 \\
$\mathrm{e}_{0}$ at $\mathrm{p}_{0}^{\prime}$ & {$[-]$} & 10.4 \\
$\mathrm{M}_{\mathrm{f}}=\mathrm{M}_{\mathrm{g}}$ (associated plasticity) & {$[-]$} & 1.75 \\
Shape factor K of the yield locus on the deviatoric $\Pi$ plane & {$[-]$} & 0.778 \\
\hline
\end{tabular}

${ }^{*}$ For the analytical function used to describe the shape of the yield locus on the $\Pi$ plane see Hibbitt et al. (2009) 
Table. 2. Index properties of the tested specimens and relevant stress levels.

\begin{tabular}{lccccccc}
\hline Sample & Gs & $\mathrm{e}_{0}$ & OC & $\mathrm{p}_{0}$ & Path & $\mathrm{p}_{\mathrm{t}}$ & $\dot{\mathrm{u}}_{\mathrm{a}}$ \\
& {$[-]$} & {$[-]$} & {$[-]$} & {$[\mathrm{kPa}]$} & & {$[\mathrm{kPa}]$} & {$[\mathrm{mm} / \mathrm{min}]$} \\
\hline Sample 1 & 1.52 & 9.8 & 0.91 & 8 & Isotropic & 74 & 0.003 \\
Sample 2 & 1.51 & 10.4 & 0.92 & 8 & Isotropic & 100 & 0.002 \\
Sample 3 & 1.50 & 10.3 & 0.91 & 8 & $\mathrm{~K}_{0}$ & 70 & 0.008 \\
Sample 4 & 1.46 & 9.7 & 0.91 & 32 & Mixed & 43 & 0.003 \\
\hline
\end{tabular}




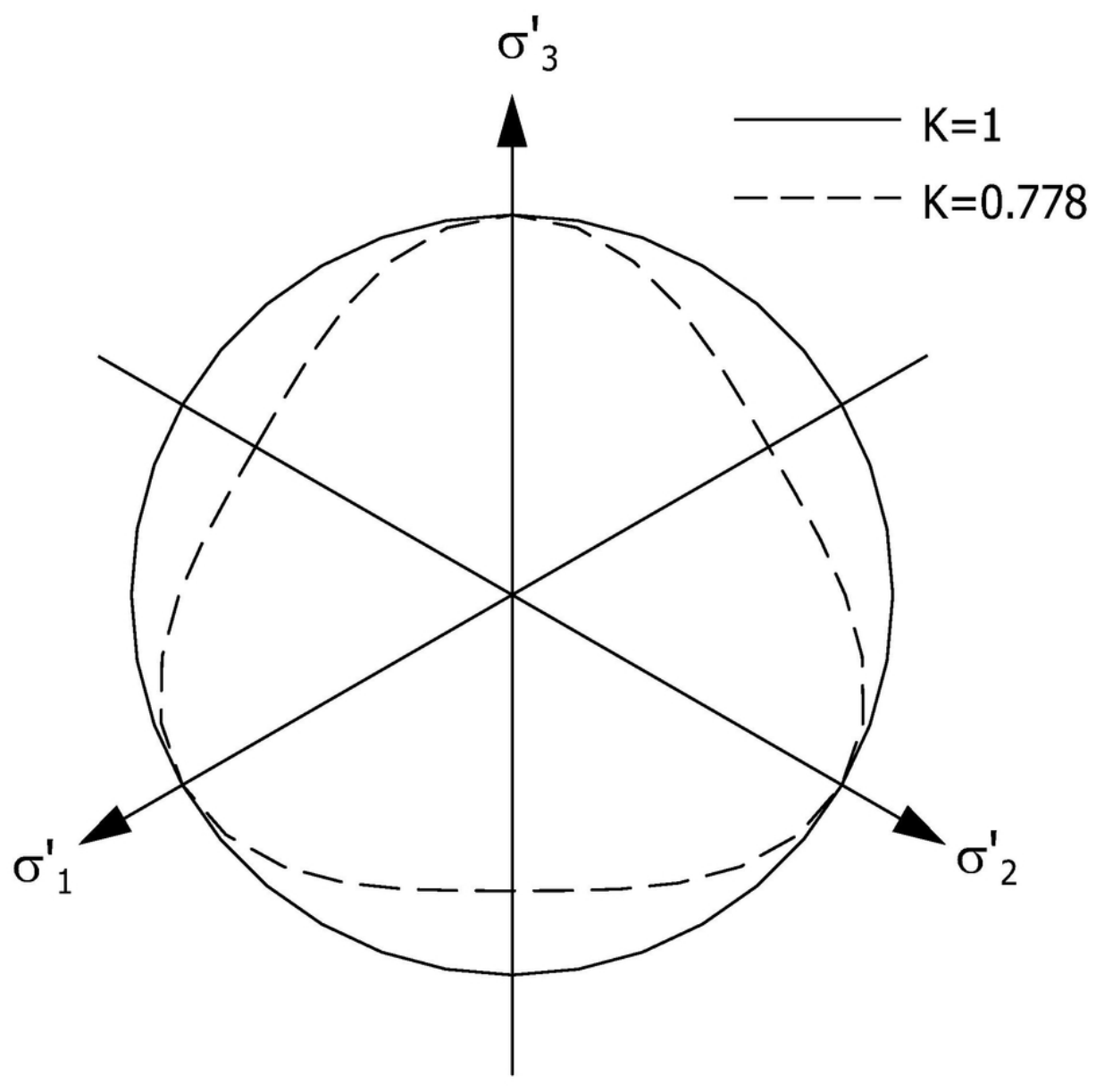

Fig. 1. Shape of the yield locus on the deviatoric $\Pi$ plane for $K=0.778$ (chosen value) and $K=1$ (von Mises) $84 \times 83 \mathrm{~mm}(300 \times 300 \mathrm{DPI})$ 


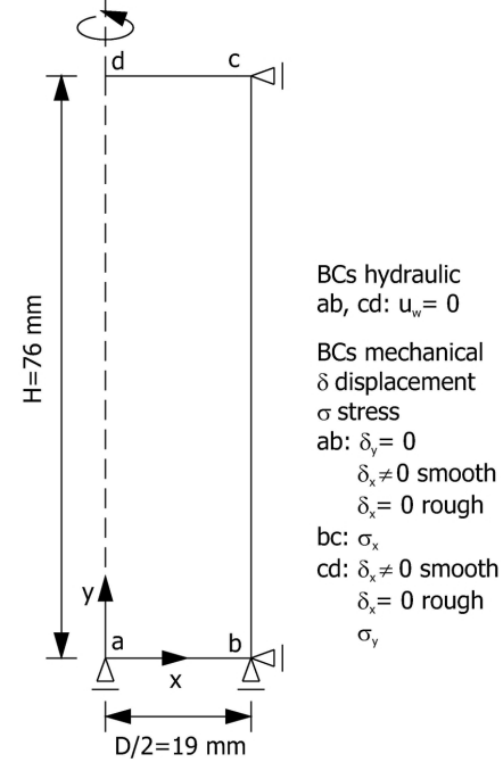

a)

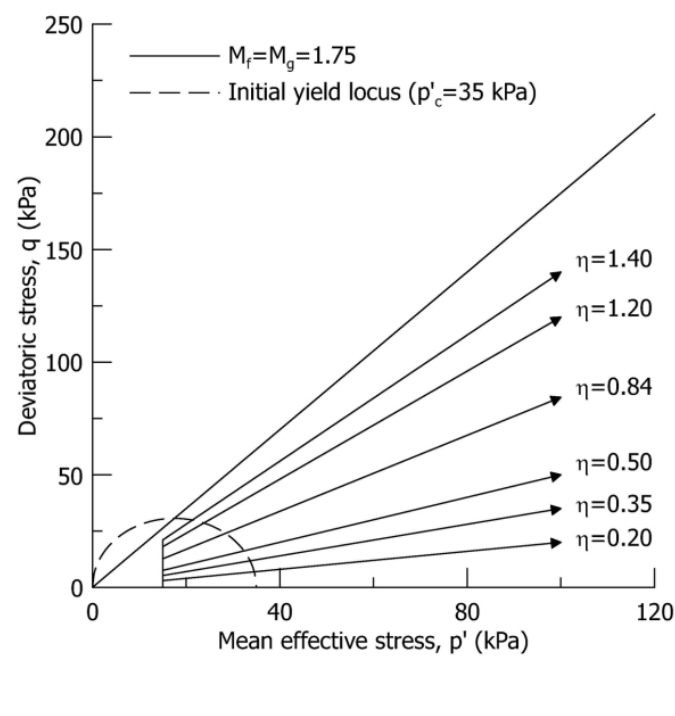

b)

Fig. 2. Sketch of the triaxial specimen with the boundary conditions used in the finite element model (a); (b) stress histories imposed to the specimen in the numerical analyses.

$186 \times 128 \mathrm{~mm}(300 \times 300$ DPI $)$ 


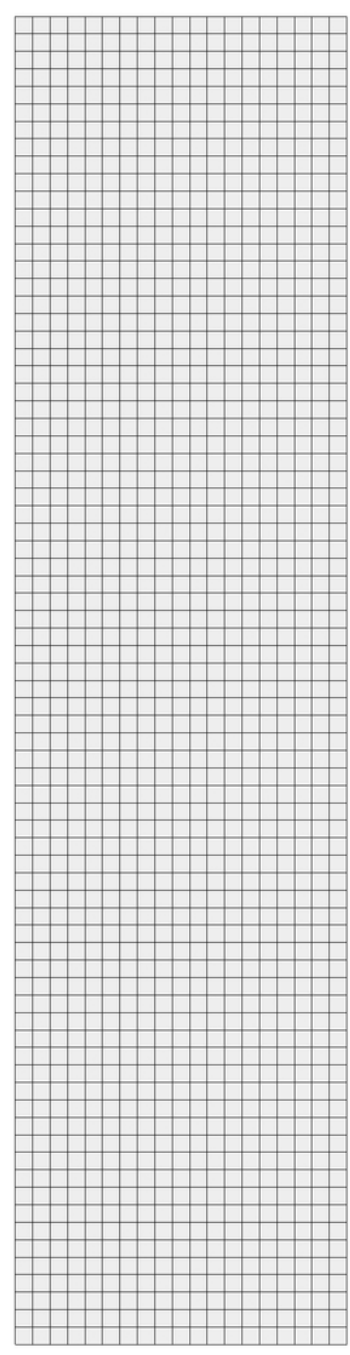

a)
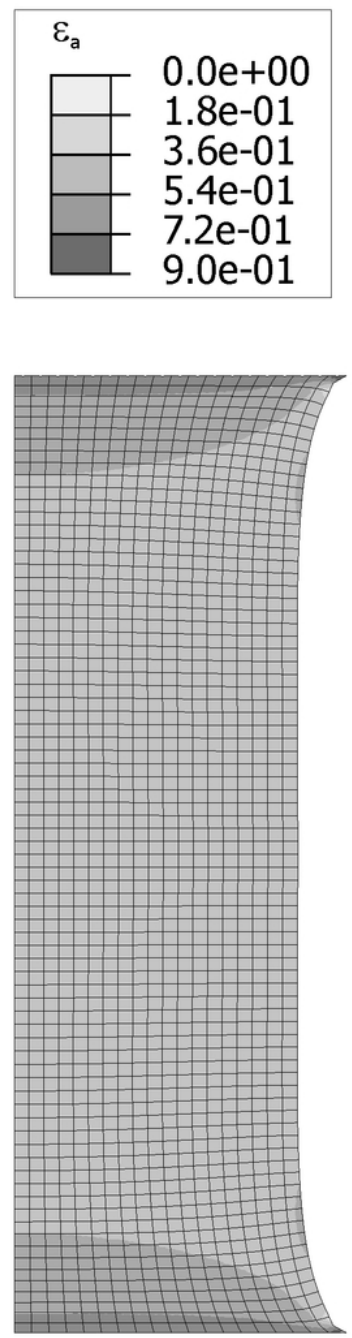

$\eta=0.35$

b)

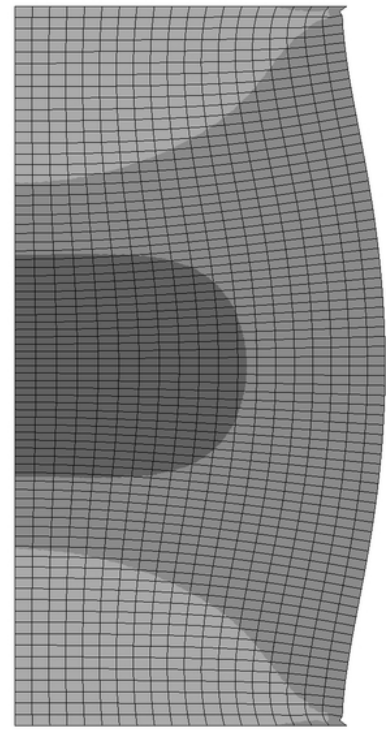

$\eta=1.40$

c)

Fig. 3. Contour plots of the axial strain from the numerical analyses: (a) undeformed configuration; deformed configuration for (b) stress ratio $\eta=0.35$ and $(c) \eta=1.40$.

$40 \times 50 \mathrm{~mm}(600 \times 600 \mathrm{DPI})$ 


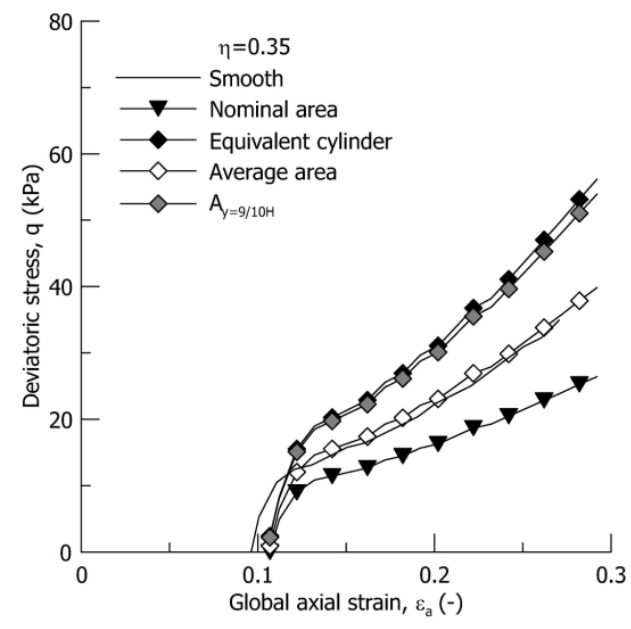

a)

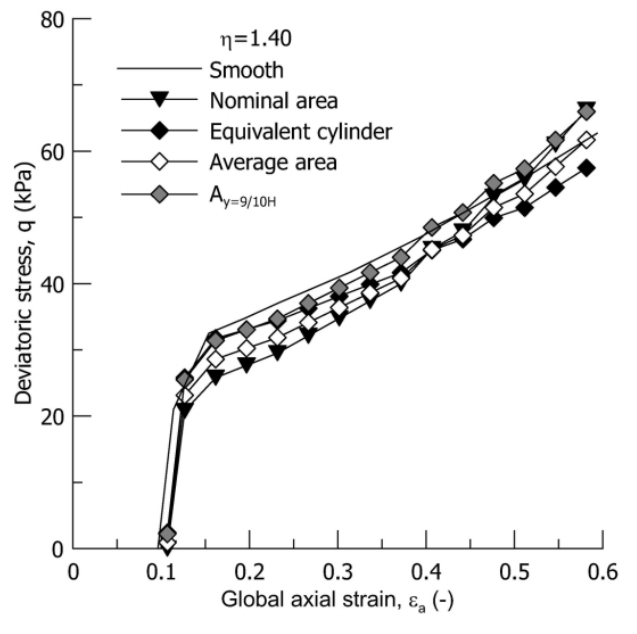

b)

Fig. 4. Comparison between the deviatoric stress-axial strain response after the four different cross sectional area corrections considered and the material response from smooth FE simulations for radial paths with (a) $\eta=0.35$ and $(b) \eta=1.40$.

$198 \times 152 \mathrm{~mm}(300 \times 300 \mathrm{DPI})$ 


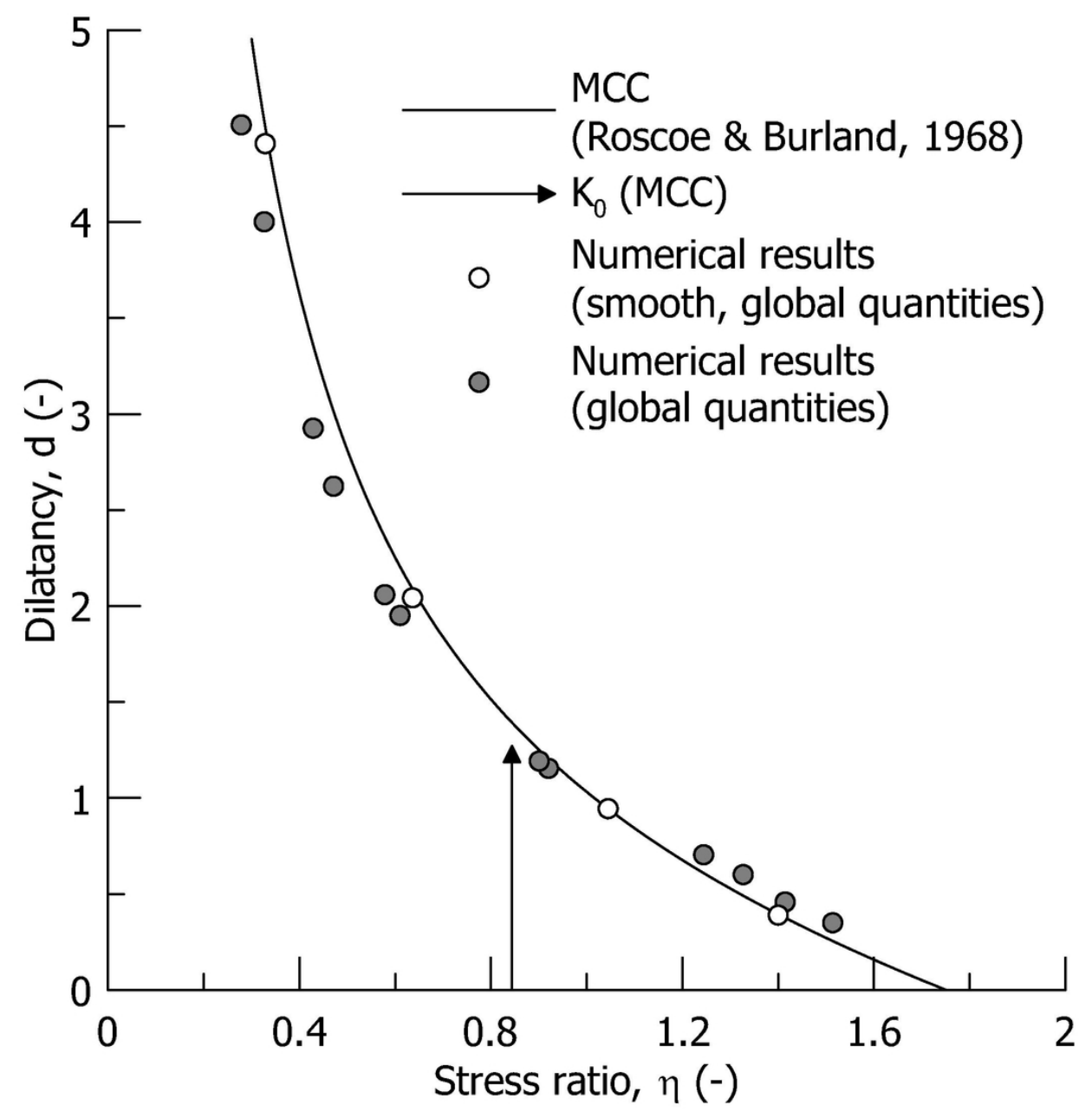

Fig. 5. Stress-dilatancy relationship $d-\eta$ from the FE results at the sample level (global quantities) for both smooth and rough end platens compared to the input MCC law.

$95 \times 98 \mathrm{~mm}(300 \times 300$ DPI $)$ 


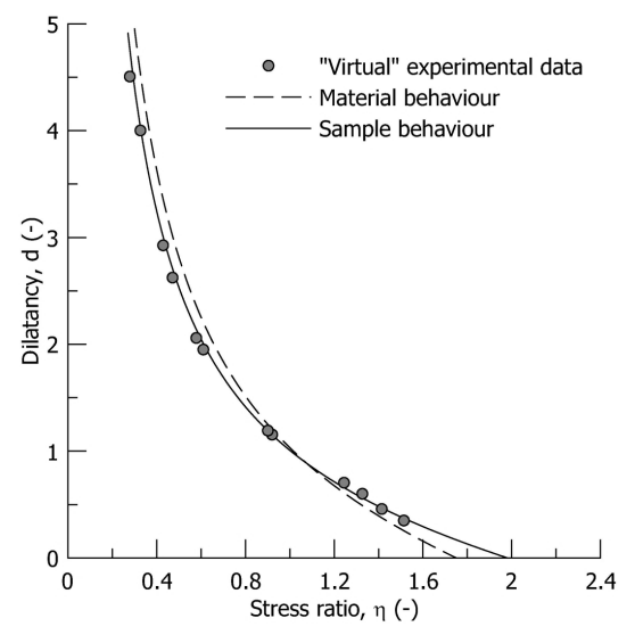

a)

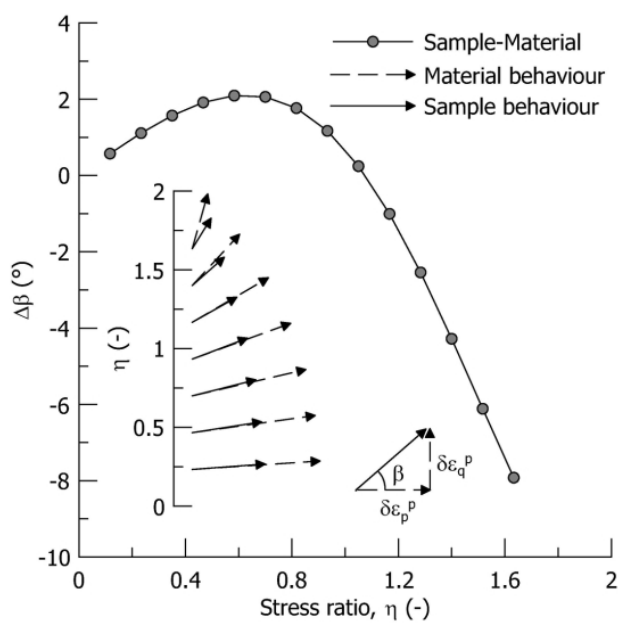

b)

Fig 6. Stress-dilatancy relationship (a) and (b) inclination of the plastic strain increment vectors obtained by fitting the results of radial paths from conventional triaxial tests with rough end platens.

$197 \times 111 \mathrm{~mm}(300 \times 300$ DPI $)$ 


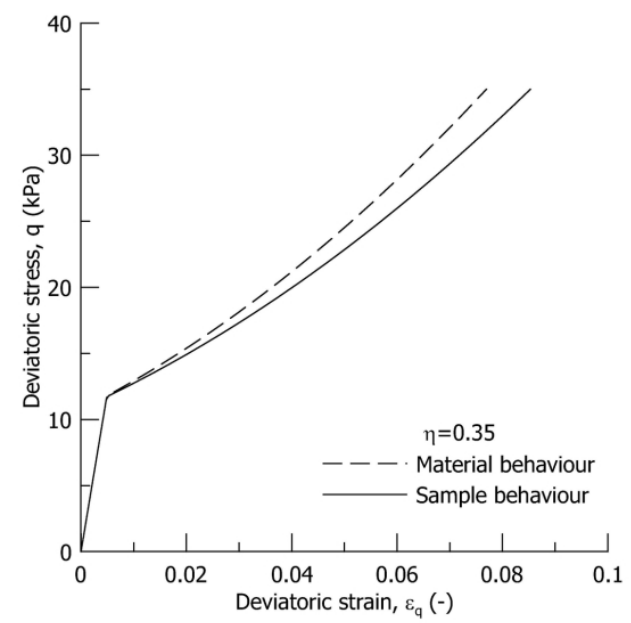

a)

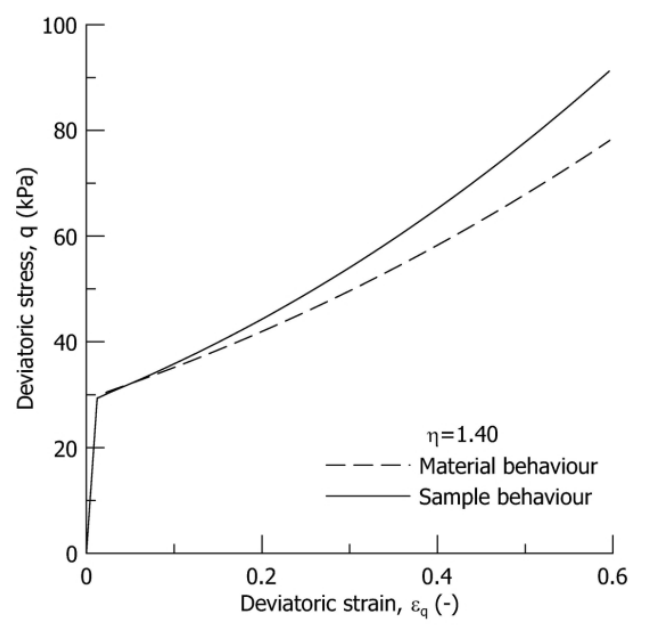

b)

Fig. 7. Comparison between material and sample behaviour as predicted from a single element test based on the results from triaxial tests with rough end platens for two radial path: $(a) \eta=0.35$ and $(b) \eta=1.40$.

$199 \times 112 \mathrm{~mm}(300 \times 300 \mathrm{DPI})$ 


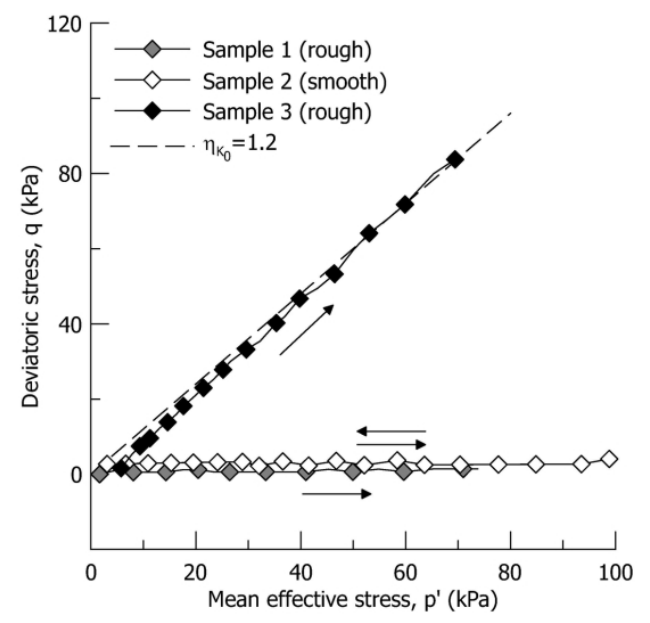

a)

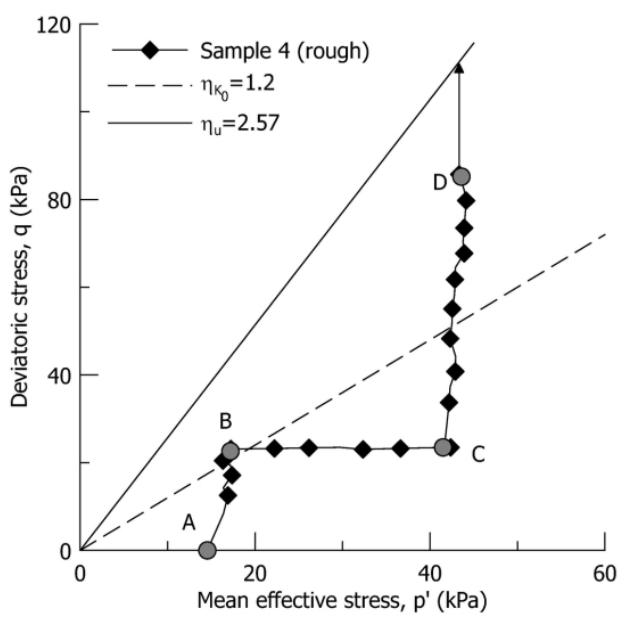

b)

Fig. 8. Experimental isotropic stress paths and $\mathrm{K}_{0}$-consolidation (a); (b) mixed isotropic-deviatoric path. $200 \times 111 \mathrm{~mm}(300 \times 300$ DPI $)$ 


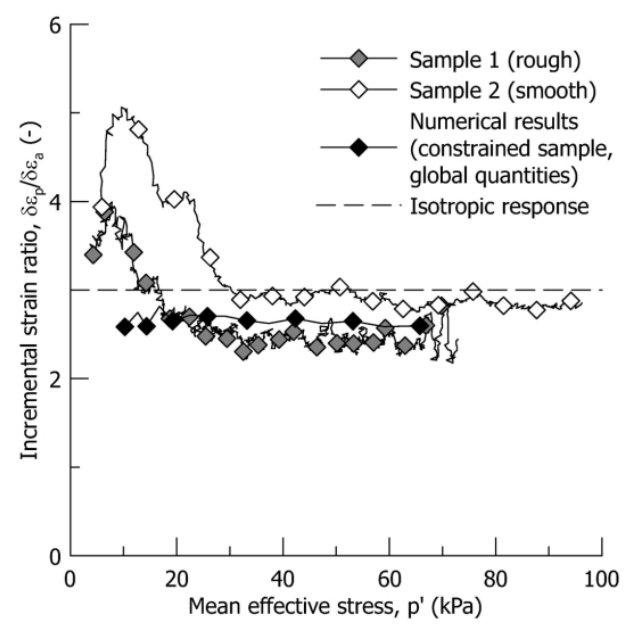

a)

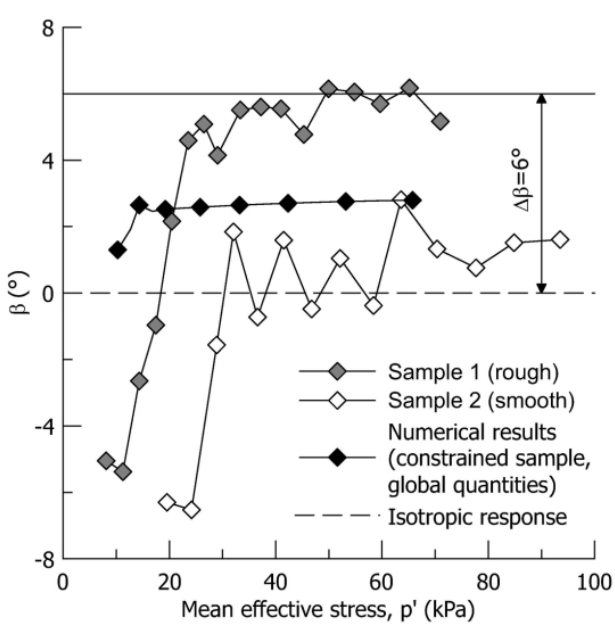

b)

Fig. 9. Incremental volumetric over axial strain ratio (a); inclination with respect to the horizontal of the plastic strain increment vectors during isotropic compression of reconstituted peat samples with rough and smooth end platens (b).

$197 \times 111 \mathrm{~mm}(300 \times 300 \mathrm{DPI})$ 


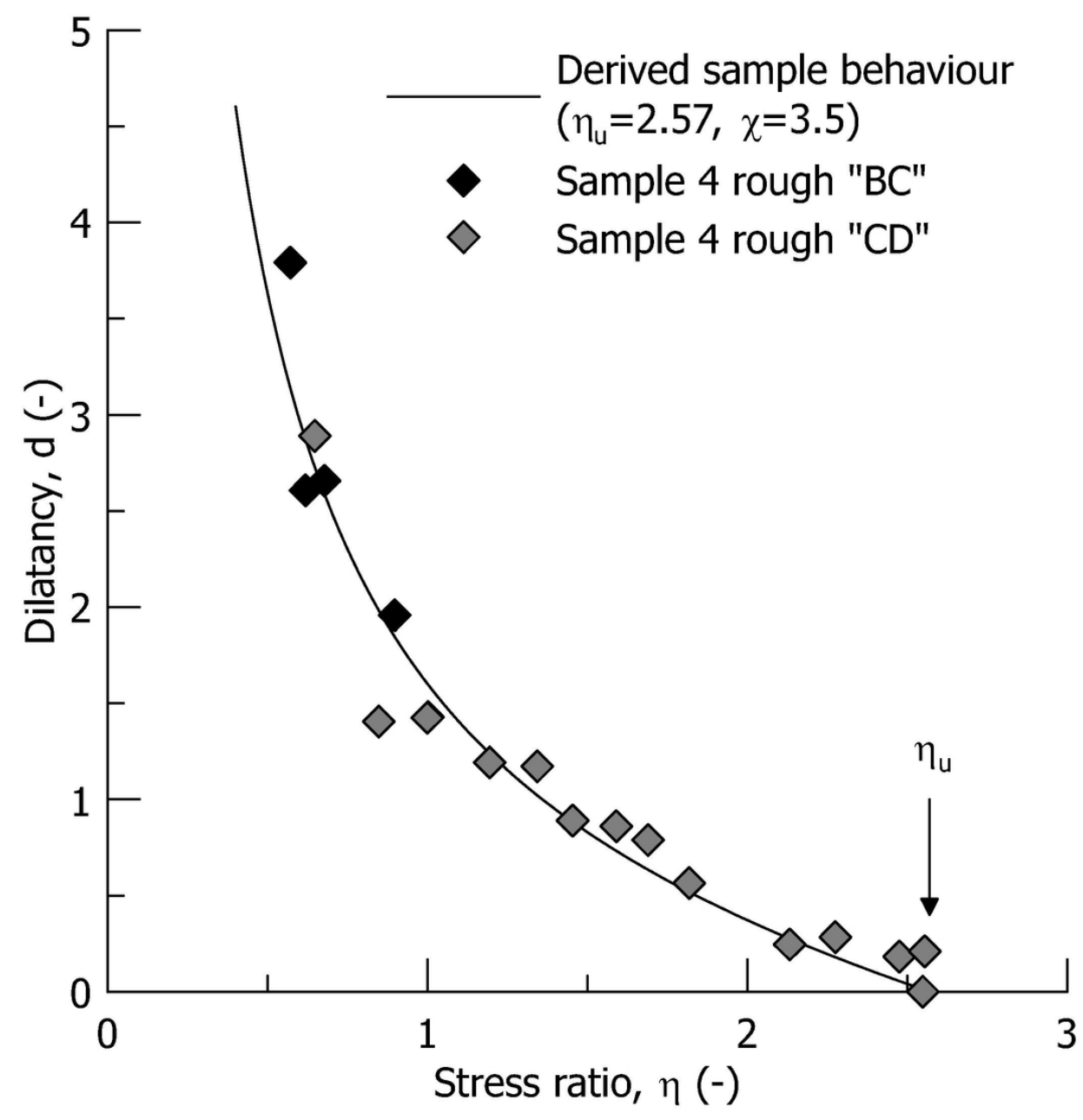

Fig. 10. Stress-dilatancy relationship derived from the experimental results on sample 4 with rough end platens.

$95 \times 98 \mathrm{~mm}(300 \times 300$ DPI $)$ 


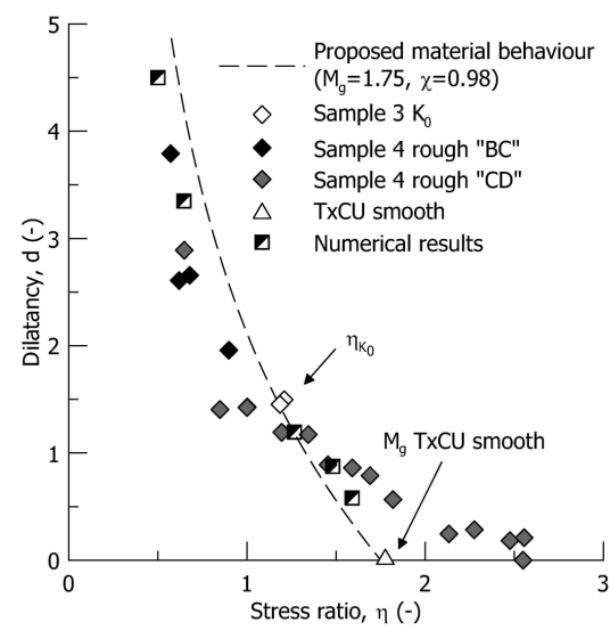

a)

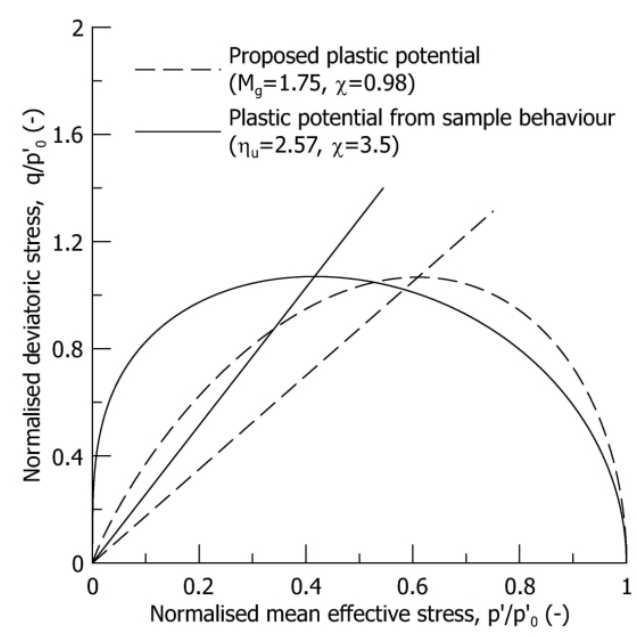

b)

Fig. 11. Proposed stress-dilatancy relationship for the tested reconstituted peat ruled out by the end restraint effect (a); plastic potential derived from for the sample behaviour and proposed plastic potential (b).

$196 \times 111 \mathrm{~mm}(300 \times 300 \mathrm{DPI})$ 